\title{
Organizational learning in a college of nursing: A learning history
}

\author{
Bret Lyman \\ Brigham Young University - Provo, bret-lyman@byu.edu
}

Lisa A. Cowan

University of Utah Health System

Hannah C. Hoyt

Follow this and additional works at: https://scholarsarchive.byu.edu/facpub

Part of the Other Nursing Commons

\section{Original Publication Citation}

Lyman, B., ${ }^{\star}$ Cowan, L., \& *Hoyt, H. (2018). Organizational learning in a college of nursing. Nurse Education Today, 61, 134-139.

\section{BYU ScholarsArchive Citation}

Lyman, Bret; Cowan, Lisa A.; and Hoyt, Hannah C., "Organizational learning in a college of nursing: A learning history" (2017). Faculty Publications. 5066.

https://scholarsarchive.byu.edu/facpub/5066

This Peer-Reviewed Article is brought to you for free and open access by BYU ScholarsArchive. It has been accepted for inclusion in Faculty Publications by an authorized administrator of BYU ScholarsArchive. For more information, please contact ellen_amatangelo@byu.edu. 


\title{
Organizational learning in a college of nursing: A learning history
}

\author{
Bret Lyman ${ }^{\mathrm{a}, *}$, Lisa A. Cowan ${ }^{\mathrm{b}}$, Hannah C. Hoyt ${ }^{\mathrm{c}}$ \\ a College of Nursing, Brigham Young University, Provo, UT, USA \\ ${ }^{\mathrm{b}}$ Resource Nursing, University of Utah Health System, Salt Lake City, UT, USA \\ ${ }^{\mathrm{c}}$ Surgical Unit, Huntsman Cancer Hospital, Salt Lake City, UT, USA
}

\section{A R T I C L E I N F O}

\section{Keywords:}

Organizational learning

Education, nursing

Learning environment

Quality improvement

Leadership

Mentorship

Character

Students, nursing

\begin{abstract}
A B S T R A C T
Background: College of nursing leaders can foster organizational learning as a means of achieving their desired organizational outcomes. Organizational learning has not previously been studied in colleges of nursing, leaving college administrators and faculty little guidance as they strive to improve outcomes in their own colleges. Objectives: The purpose of this study was to discover new insights related to organizational learning in a college of nursing.

Design: The learning history method was used to document and describe organizational learning in a college of nursing.

Setting: This study was conducted with a college of nursing situated in a private, religious-based university in the western United States.

Participants: Six stakeholders and 16 individuals familiar with the college's history were purposively recruited for this study. Participants included college administrators, faculty, students, alumni, and individuals with university-level responsibilities related to the college.

Methods: Semi-structured interviews and college artifacts were used to gather data. Data was reviewed and themes identified through a process called "distillation."

Findings: The college's vision, "Learning the Healer's Art" provides purpose and motivation within the college. Four themes provide additional insight into how the college established a learning culture and fosters behavior conducive to organizational learning: (1) Character and Quality, (2) Long-Term Perspective, (3) Collaborative Leadership and Adaptation, and (4) Mentoring.

Conclusion: College of nursing leaders can foster organizational learning and pursue improvement within their colleges. Recommended actions include developing a shared vision for the college, building a cadre of qualified faculty and students who have strong personal character, maintaining a long-term perspective, using a collaborative approach to leadership and adaptation, and facilitating mentoring.
\end{abstract}

Organizational learning is a highly context-dependent process through which organizations progress toward achieving their desired outcomes. Examples of desired outcomes for a college of nursing (CON) include student achievements, faculty publications, and leadership in the profession. Organizational learning has been studied in a variety of business and industrial settings (Amidon, 2008), hospital units (Lyman et al., 2017, in press), and higher education (Kuzmicz, 2015; Lawler and Sillitoe, 2013; Örtenblad and Koris, 2014). However, extensive searching in major databases (CINAHL, MEDLINE, Business Source Premier, Academic Search Premier, ERIC, and PsycINFO) revealed no research on organizational learning in CONs. A primary purpose of this study was to discover new insights related to organizational learning in a CON that may guide nursing faculty and administrators as they strive to improve outcomes in their own colleges.

\section{Methodology}

The research design selected for this study was a "learning history" (Bradbury et al., 2015; Kleiner and Roth, 1996). Learning histories can be used to study organizational learning and the context in which the learning occurred. Learning histories document past learning in an organization and stimulate a collective reflection process that can serve as a foundation for future collective reflection and learning within the organization (Bradbury et al., 2015).

\subsection{Setting}

This study was conducted with a CON situated in a private, religious-based university in the western United States. The CON employs

\footnotetext{
* Corresponding author at: 562 Spencer W. Kimball Tower, Provo, UT 84603, USA.

E-mail address: Bret-Lyman@byu.edu (B. Lyman).
} 
Table 1

Participant demographics.

\begin{tabular}{ll}
\hline Demographic & $N=16$ \\
\hline $\begin{array}{l}\text { Gender } \\
\text { Female }\end{array}$ & \\
Male & $13(81.25 \%)$ \\
Role & $3(18.75 \%)$ \\
Faculty/Administrator & \\
Tenure track & $8(50 \%)$ \\
Tenured & $3(0.375 \%)$ \\
Student & $5(0.625 \%)$ \\
Alumni & $2(12.5 \%)$ \\
Staff & $3(18.75 \%)$ \\
\end{tabular}

approximately 40 tenured or tenure-track faculty, 12-16 adjunct faculty, and 11 administrative/staff personnel. Annually, the program graduates approximately 120 baccalaureate and 15 masters students.

\subsection{Sample}

Purposive sampling was used to recruit participants with insights relative to the college being studied. Inclusion criteria were: individuals who currently work in the college or who have worked in the college in the past three years, administrators and auxiliary staff who have direct influence on operations in the college, and other individuals identified during the course of the study as having relevant experience with, or knowledge of the college. In all, 16 individuals were interviewed, including a university administrator and CON faculty, administrators, staff, students, and alumni. The demographic and professional characteristics of the sample are listed in Table 1.

\subsection{Data Collection}

Because organizational learning is theorized as a path to achieving important organizational outcomes (Argote and Miron-Spektor, 2011), the researchers began data collection by convening six stakeholders who had deep experience with the organization and its outcomes. Four stakeholders were college faculty, staff, and administrators, and two had university-level responsibilities related to the college. Collectively, these individuals had over 70 years of direct experience with the college. After obtaining consent, researchers invited the stakeholders to identify 3-5 accomplishments the college is particularly proud of. Using the process described in the "Data Analysis" section, researchers grouped the stakeholders' feedback into five main outcomes: learning the Healer's art, preparing students for clinical practice, leading in the community and profession, improving global health, and retaining excellent faculty. These achievements informed the rest of the data collection process.

Next, the research team conducted interviews with individuals with direct knowledge of or experience with one or more of the five outcomes. Consenting participants were asked, "Which notable outcome(s) would you like to talk about?" and "How do you think the college has been able to achieve that notable outcome?" Follow-up questions allowed researchers to explore the participant's progression of thought, including his or her assessment of the events, behaviors, and other factors contributing to the notable outcome. Specifically, researchers sought to understand how the organization has adapted, changed, and innovated to achieve its notable outcomes. In total, 16 interviews were conducted, ranging in length from 18 to $62 \mathrm{~min}$. All interviews were recorded and transcribed verbatim.

In addition to interviews, relevant artifacts were gathered to document institutional learning pathways to the notable outcomes. Artifacts included documents prepared for national accreditation visits, program evaluations, faculty governance council meeting minutes, and a history of the college, published in commemoration of the college's 60th anniversary. Formal documents, such as the college creed, mission statement, values statement, and website rounded out the archival data.

\subsection{Data Analysis}

Data were analyzed using a process called "distillation" (Bradbury et al., 2015), which bears some similarity to grounded theory. Researchers individually reviewed the transcribed interviews and artifacts and identified major concepts. Then the researchers shared these concepts with each other, grouping similar concepts, refining labels for the concepts, and identifying new concepts. Additional interviews were conducted when missing or unclear information was noted. The researchers collaboratively grouped the concepts into themes, around which the written learning history was organized. The themes were then reviewed by the researchers to ensure they accurately reflected the data. To ensure trustworthiness, the synthesized data was validated (Bradbury et al., 2015) with the key stakeholders.

\section{Findings}

The learning history emerging from this process documented several decades of organizational learning. Findings included participants' attention to the historical development of the college; an emphasis on "Learning the Healer's Art," which serves as a unifying vision for the college; and four themes related to achieving the college's notable outcomes.

\subsection{Historical Development}

The origins of the CON were salient for many participants. Several mentioned that during the late 1800s, the college's sponsoring organization helped train women in midwifery and medicine to address the healthcare needs of congregants. That training evolved into a hospitalbased diploma nursing program, and then, in 1952, into a universitybased baccalaureate degree program.

The college's history is passed on to students and faculty during orientations, college-sponsored events, and convocations. Several CON faculty noted that the historical foundations of the college motivate them as they prepare nurses "for a promising professional future and a Christ-centered life."

\subsection{Unifying Vision}

As part of the college's 40th anniversary, a committee defined the college's motto, which acts as a unifying guide to learning, teaching and practicing within the profession. The motto, "Learning the Healer's Art," refers to Jesus Christ as the master Healer. The words come from a hymn that is familiar to most of the institution's students and other stakeholders. Participants indicated the motto helps faculty and students focus their hands, hearts, minds, and the spirit of Christ into the holistic healing process. One faculty member described the essence of the Healer's Art as combining "the spiritual aspects of compassion and empathy... with knowledge-the best of science and skills."

Informants also said the motto encourages college members to look beyond prejudices as they connect "with people in their circumstances... where they are, and not making assumptions about where they ought to be." One staff member described students, faculty, and alumni as practicing with "compassion, faith and inspiration." Another said that local hospital leaders describe the college's students as "different, for the better."

Additionally, the motto helps the CON generate and allocate resources. The Dean "refer[s] to Learning the Healer's Art whenever... she meets with the president's council," when talking with donors, discussing resource planning, and guiding faculty discussions. In recent years, the faculty developed a creed, based on the motto, to guide faculty behavior. The creed encourages faculty to treat all organization 
members with respect, collaborate openly, and express gratitude and optimism.

In short, the college's emphasis on "Learning the Healer's Art" seems to function as a vision for the college, permeating the college's culture, and providing a deep purpose and shared motivation for many activities within the college. Arguably, each of the other themes mentioned in interviews as drivers of the CON's success could relate back to the "Healer's Art."

\subsection{Emerging Themes}

Four emerging themes offer insight into the context and behaviors related to organizational learning within the college: (1) character \& quality, (2) long-term perspective, (3) collaborative leadership \& adaptation, and (4) mentoring.

\subsubsection{Character and Quality}

Participants frequently attributed progress toward the college's notable outcomes to the character and quality of its faculty and students. "Character" in our analysis refers to an individual's ethical standards and behavior, as well as to his or her personal spirituality-all elements frequently mentioned by participants. We use the term "quality" to encompass ideas related to professional excellence. Exceptional character and quality in faculty and students are hallmarks of the college and are recognized within the professional community. One faculty member said, "[what] sets the [students] apart... [is their] high degree of character, integrity, honesty." The college places a high priority on attracting people with these attributes, uses rigorous criteria for admission and hiring, and intentionally develops character and quality in faculty and students.

Students and faculty said they were attracted to the college for a variety of reasons. A predominant reason was the influence of the university's sponsoring religious organization, which emphasizes high standards of personal character and conduct. An administrator said that many faculty and students tell her they felt spiritually "drawn [and] directed" to teach at or attend the college. Another factor that attracts high-quality faculty and students is the college's "high reputation...in the community." Faculty, staff, and administrators touted the college's high pass-rates on a standardized licensure examination (NCLEX-RN), positive reputation with employers, expansive global health program, and affordability. These factors motivate highly qualified faculty and students to apply for positions in the college.

Rigorous admissions and hiring processes further ensure the character and quality of faculty and students. To be eligible for hire or admission, faculty and students must agree to abide by the religious organization's behavioral standards. One faculty member said "we recruit faculty who are innovative, excited, and enthusiastic." An administrator emphasized the importance of recruiting faculty who are "not just the best in their discipline, but role models of life." A staff member described the admissions process as prioritizing community service, academic performance, standardized test scores, writing ability, and personal fit for the college, ensuring the students admitted are "the brightest of the bright."

Once they are accepted to work or study in the college, characterdevelopment remains a strong focus for faculty and students. Faculty help students develop character in several ways, including role modeling compassion, sharing character-building spiritual and clinical experiences, and using discussions and assignments to prompt characterfocused reflection. Many students also develop character by serving an 18- to 24-month religious mission. A faculty member expressed that the mission experience increases students' maturity level as communicators and leaders. A staff member added that these students develop "more cultural awareness and language abilities (fluent in Spanish, Mandarin, etc.)." Because students role model strong character, fellow students and faculty members are motivated to do the same.

The quality of faculty and students improves through their experiences in the program. Faculty strive to stay current in their respective specialty areas. Several faculty and administrators reported that faculty receive substantial support to advance their research trajectories and improve as teachers. This support helps faculty advance their own scholarship and provide students with a high-quality, relevant educational experience. Students mentioned feeling prepared for professional practice by being held to high academic and professional standards while participating in clinical, classroom and simulation experiences.

\subsubsection{Long-term Perspective}

The college demonstrates a long-term perspective in the way it approaches various initiatives. Long-term perspective means considering the long-term implications of decisions, rather than just the immediate outcomes. One element contributing to this long-term perspective is the sponsoring religious organization's focus on having an "eternal perspective." When contemplating the college's purpose in the context of an eternal timeline, college leaders are more apt to anticipate the long-term implications of initiatives. The long-term perspective is manifested in the way the college recruits and retains faculty, implements change, and invests in maintaining community relationships.

The college recognizes its long-term success depends on recruiting and retaining faculty from a small pool of applicants who meet the college's strict hiring criteria. Based on a recommendation from a religious leader that, "if you pray, they will come," college administrators frequently pray for divine guidance regarding faculty searches. In addition, the college developed a "strict and rigorous process" for tracking potential faculty, sometimes for years, until they are ready to apply for a position with the college. This system allows the college to court and recruit qualified individuals who can contribute to the college's longterm needs. Strong faculty retention can, in part, be attributed to the use of internally funded faculty positions. Administrators report that, because faculty members do not need to rely on external funding as a portion of their salary, they feel more secure in their faculty positions.

The college takes a thoughtful approach to change. For example, programs are piloted on a small scale before they are implemented broadly. College leaders rely on their long-term perspective to persist through the change process, even when positive results are not immediately apparent. For example, years ago, faculty were interested in offering students a global health experience and leveraged their international connections to pilot an elective global health course in two locations abroad. Although offering students these experiences was challenging, faculty persisted in developing the college's global health program. As more faculty came to recognize that the value of the program was not just "learning about another culture (language and food); it's about accepting and loving," they expanded their vision of what the program could become. Now, the annual global health program operates in 10 locations and all students are required to complete a global health clinical experience. Students say these "life-changing experiences" will have a life-long impact on the way they view patients from various ethnic and cultural backgrounds. More recently, faculty have used a similar approach to develop and pilot courses in stress management, employment strategies, test-taking strategies, etc.

The college is aware that its long-term success depends on having strong external relationships and a positive public image. To address these needs, the college invested in hiring a public relations specialist who coordinates events that strengthen relationships with clinical partners, faculty, students, alumni, and donors. The public relations specialist saw the need for alumni events as alumni were reporting that they felt, "all alone in the area; there's no other people [from our CON] here." Events to connect people in various locations have provided opportunities for alumni to "connect, socialize and reminisce." The public relations specialist works to "promote the good" aspects of the college's image by publicizing faculty and student achievements via social media, online videos, print media, sponsored booths at conferences, and so forth. 


\subsubsection{Collaborative Leadership \& Adaptation}

Faculty and students frequently collaborate to achieve desired outcomes within the college. Collaborative leadership and adaptation refers to faculty, including college leaders, working closely with each other and students, to adapt and improve the college.

Faculty collaborate with students to improve the college. One example is course councils, where faculty and students meet bi-monthly to discuss nursing courses, including course elements that help or hinder student success, as well as other pertinent concerns. After course council meetings, "faculty communicate and improve courses according to what students bring up in those meetings." For example, some students noted that scheduled mid-term examinations coincided with the deadline for a major research paper and brought this to the course council for discussion. The course faculty, in turn, changed the dates of the exams and paper deadlines. Students told faculty that they felt better prepared to succeed on the exams and the paper, and felt empowered to use their voices in a professional, productive way. Another example of faculty-student collaboration was the development of a career strategies course. The course was designed by a student as part of a faculty-mentored project. Faculty continue to change and improve the course based on student feedback.

Faculty collaborate with each other to adapt the program to better achieve its outcomes. For example, faculty recognized that NCLEX-RN pass rates did not meet the college's expectations. As a result, college administrators and faculty selected a commercial NCLEX-RN test-preparation package, integrated it throughout the nursing program, and developed an elective course focused on preparing students for the NCLEX-RN. The college has since noted a consistent 10-15\% increase in passing rates among graduates. Recently, one faculty member, who was informally coaching students on test-taking, noticed many students struggled with NCLEX-style questions in their nursing courses. She further enhanced test-taking support for students by developing an elective course on effective test-taking strategies that is available to students at all levels within the program. Students report feeling better prepared for NCLEX-style questions, and earning improved test scores after taking this course.

\subsubsection{Mentoring}

Mentoring in the college occurs in many forms: one-on-one time with students, mentored research, faculty mentoring other faculty, and students helping other students. Through mentoring, faculty and students show support and compassion for one another.

Faculty dedicate several hours weekly to one-on-one mentoring with students. Faculty say they strive to be aware of student needs so they can use planned and unplanned mentoring opportunities to meet those needs. Mentoring happens during regular academic activities (e.g. office hours, clinical experiences, and classroom lectures), facultymentored research activities, global health experiences, and student government activities. During regular academic activities, faculty try to share relevant examples from their experiences, guide students' critical thinking, and give students encouragement and feedback. Several donor-funded internal funding mechanisms support faculty-mentored research experiences for students. Through these experiences, many students actively engage in nursing scholarship and present their work at professional conferences. The global health experience also provides rich opportunities for mentoring. During these experiences, faculty mentor students over multiple weeks as they are immersed in the culture, traditions and healthcare practices in the global setting. Because the global health groups are small, students develop personal relationships with faculty and report having opportunities to ask questions about various topics, such as work-life balance, professional issues in nursing practice, and clinical skills. Additionally, students who serve in the college's Student Nurses Association are mentored by two faculty advisors, who support the students as they lead the organization and travel to national conventions to raise their voices and improve the discipline. Faculty-student mentoring also occurs with student employees who work in the nursing learning center (skills lab, simulation lab, reference library), as teaching assistants, or on the public relations team.

Faculty also mentor each other. When new faculty are hired, experienced faculty are assigned to mentor the new faculty through the promotion and tenure process. New faculty members receive training in the process through formal and informal mentoring sessions, and receive detailed guidance from documents established by college leaders. Faculty are also mentored in their scholarship and research trajectories during annual stewardship interviews with the Dean or Associate Dean. Faculty report receiving expert guidance during these interviews as they review their performance over the past year and set goals for the future.

Students mentor other students in formal and informal ways. Some students work as teaching assistants for certain difficult classes, which often opens the door to ongoing student-student mentoring relationships. Other students serve as leaders in the college chapter of the Student Nurses Association, where they plan programs and events to help fellow students develop professionally and to manage the stress associated with school. Informally, students mentor each other by organizing study groups, using text messaging and social media to remind each other about due dates, and providing tutoring to other students in the program.

\section{Discussion}

These findings offer insight into organizational learning in a CON. Faculty members and administrators in this particular college created a culture conducive to organizational learning by establishing a shared vision, recruiting faculty and students who fit organizationally relevant criteria, and maintaining a long-term perspective. Within this environment, certain behaviors-collaboratively leading change, and providing strong mentoring, teaching, and learning-contribute to organizational learning and achievement of the college's notable outcomes.

\subsection{Creating a Culture of Learning}

To achieve their desired outcomes, college leaders need to create a culture of learning (Adjieva and Wilson, 2002; Ponnuswamy and Manohar, 2016), questioning, and quality improvement (Freed and Klugman, 1996). College leaders can establish a culture that is conducive to organizational learning by developing a unifying vision, emphasizing quality and character in their faculty and students, and maintaining a long-term perspective.

\subsubsection{Vision}

A unifying vision is important to becoming a learning organization (Hodgkinson, 2000; Roberts, 1994; Senge, 1990; Voolaid and Venesaar, 2011). Unfortunately, many colleges do not use a vision to guide behavior within their organizations (Mulligan, 2014). We found that the college's motto, "Learning the Healer's Art," served as a shared vision among the faculty, staff, and students, and that it was vital to the college's learning. This finding helps validate the importance of establishing a shared vision in an institution of higher education. Our findings also suggest the importance of using a creed, or clear code of conduct, to operationalize the college's vision.

\subsubsection{Character \& Quality}

Lin (2004) suggests that the collective expertise of individuals in an organization directly influences its potential for organizational learning. We found that the college's faculty and students were highly qualified individuals of reputable character, who contributed to collaborative efforts that improved the outcomes of teaching and learning. This finding validates the conventional understanding that high-quality faculty are foundational to achieving quality in CONs. Although Senge 
(1990) suggests that leaders should function as stewards-taking responsibility to care for the needs of those in their organizations-we did not find empirical data in the literature to support the relationship between strong character and organizational outcomes. This paucity may be related to the difficulty Sellman (2007) describes in evaluating an individual's moral character. Still, our finding regarding reputable character represents a unique contribution to the study of organizational learning in CONs.

\subsubsection{Long-term Perspective}

Adaptation is a fundamental element of a learning culture. Futuredriven leaders adapt practices according to new research and knowledge, and then sustain those changes (Kumar and Idris, 2006). We found that members of the college maintain a long-term perspective when planning changes to the curriculum, piloting new programs, recruiting and orienting faculty, and investing in public relations. This finding validates the importance of maintaining a long-term perspective while implementing change. The college's use of a public relations team also aligns well with Mulligan's (2014) suggestion that effective communication with external stakeholders can foster organizational learning in institutions of higher education.

\subsection{Behaviors Conducive to Learning}

Fostering organizational learning is an important step college leaders can take toward achieving their desired outcomes-fostering collaborative leadership and mentoring.

\subsubsection{Collaborative Leadership \& Adaptation}

Collaborative leaders facilitate reflection and gather feedback when making decisions (Cambridge, 2008; Freed and Klugman, 1996; Mulligan, 2014; Senge, 1990) by creating opportunities for dialogue and listening, particularly to those with under-represented voices (Mulligan, 2014; White and Weathersby, 2005). The college's leaders demonstrate this principle by supporting faculty and students in their respective governance structures. Through these governance structures leaders solicit faculty and student feedback while developing new teaching methods, creating new simulation scenarios, and establishing new support courses. Additionally, Kezar (2007) suggests that academic leaders use events and focus groups to facilitate interactions with students. The dean in this college meets with student focus groups on a regular basis and attends the students' global health experiences.

\subsubsection{Mentoring}

Lin (2004), suggests that universities should establish counselling and mentoring for faculty to exchange teaching ideas, as well as simplify the means for faculty to continue their education. This college provides mentoring experiences for both faculty and students. For example, faculty mentor each other, faculty mentor students, and students mentor each other. The extensive mentoring program for new faculty in this college is especially notable.

\subsection{Recommendations}

Findings from this study can be applied to CONs desiring to become learning organizations. When establishing a culture of learning, college leaders can focus on developing a vision, improving the character and quality of members within the organization, and maintaining a longterm perspective. CONs can foster organizational learning through behaviors such as promoting collaborative leadership and adaptation, and providing adequate mentoring opportunities.

\subsection{Limitations and Future Research}

Although these results represent important insights regarding organizational learning in CONs, additional studies are needed to validate their generalizability. This particular college is situated in a private, religious-based institution, giving it a unique organizational context. Although interviews were conducted until saturation was reached, it is possible that faculty or students who were not interviewed have different perspectives. Because learning histories are focused on notable outcomes, negative aspects of the college's history or ineffective learning behaviors were not elicited during the interview process. Because this study is retrospective, interviewees' biases and ability to recall details may have also influenced our findings.

This study should be replicated with other CONs to determine the generalizability of these findings. Grounded theory studies could be used to generate a theory of organizational learning in CONs, which could serve as a valuable foundation for additional research and interventions to facilitate organizational learning.

\section{Conclusion}

The primary purpose of this study was to discover new insights related to organizational learning in a college of nursing that may guide nursing faculty and administrators as they strive to improve outcomes in their own colleges. Findings included four themes associated with organizational learning in a CON: Character \& Quality, Long-Term Perspective, Collaborative Leadership \& Adaptation, and Mentoring. College leaders can take specific steps to create a culture of learning and to foster behaviors conducive to learning, which will allow them to achieve their own desired outcomes.

\section{Funding/Support}

This study was supported by the Brigham Young University College of Nursing.

\section{Acknowledgements}

The authors thank the participants for sharing their insights and knowledge regarding the college's history and performance.

\section{References}

Adjieva, M., Wilson, M., 2002. Exploring the development of quality in higher education. Manag. Serv. Qual. 12 (6), 372-383. http://dx.doi.org/10.1108/ 09604520210451858.

Amidon, S., 2008. The learning history: analyzing an emerging genre. J. Bus. Commun. 45 (4), 451-482. http://dx.doi.org/10.1177/0021943608319387.

Argote, L., Miron-Spektor, E., 2011. Organizational learning: from experience to knowledge. Organ. Sci. 22 (5), 1123-1137.

Bradbury, H., Roth, G., Gearty, M., 2015. The practice of learning history: Local and open system approaches. In: Bradbury, H. (Ed.), The SAGE Handbook of Action Research, 3rd ed. Thousand Oaks, CA, SAGE, pp. 17-30.

Cambridge, D., 2008. Universities as responsive learning organizations through competency-based assessment with electronic portfolio. J. Gen. Educ. 57 (1), 51-64.

Freed, J.E., Klugman, M.R., 1996. Higher education institutions as learning organizations: The quality principles and practices in higher education. In: ASHE Annual Meeting Paper.

Hodgkinson, M., 2000. The role of higher education institutions in facilitating organization learning: with HRD managers. Hum. Resour. Dev. Int. 3 (3), 361-375.

Kezar, A.J., 2007. Learning from and with students: college presidents creating organizational learning to advance diversity agendas. NASPA J. 44 (3), 578-609. http://dx. doi.org/10.2202/1949-6605.1837.

Kleiner, A., Roth, G., 1996. Field Manual for a Learning Historian. MIT-COL and Reflection Learning Associates, Inc., Cambridge, MA.

Kumar, N., Idris, K., 2006. An examination of educational institutions' knowledge performance. Learn. Organ. 13 (1), 96-116. http://dx.doi.org/10.1108/ 09696470610639158.

Kuzmicz, K.A., 2015. Benchmarking in university development towards a learning organisation. Int. J. Contemp. Manag. 14 (2), 89-101.

Lawler, A., Sillitoe, J., 2013. Facilitating 'organisational learning' in a 'learning institution.'. J. High. Educ. Pol. Manag. 35 (5), 495-500. http://dx.doi.org/10.1080/ 1360080X.2013.825415.

Lin, H., 2004. A study of learning organization and faculty development in higher education (Doctoral dissertation) In: Retrieved from ProQuest Dissertations and Theses.

Lyman, B., Shaw, L., Moore, C., 2017b. Organizational learning in an orthopaedic unit. Orthop. Nurs. 36 (6), 424-431. http://dx.doi.org/10.1097/NOR. 0000000000000403. 
Lyman, B., Ethington, K.M., King, C., Jacobs, J.D., Lundeen, H., 2017a. Organizational learning in a cardiac intensive care unit. Dimens. Crit. Care Nurs. 36 (2), 78-86. http://dx.doi.org/10.1097/DCC.0000000000000233.

Mulligan, M.C., 2014. Perceptions of general education deans and department chairs of their colleges as learning organizations (Order No. 3584777) In: Available from ProQuest Dissertations \& Theses Global. (1549432348).

Örtenblad, A., Koris, R., 2014. Is the learning organization idea relevant to higher educational institutions? A literature review and a "multi-stakeholder contingency approach.”. Int. J. Educ. Manag. 28 (2), 173-214. http://dx.doi.org/10.1108/ijem-012013-0010.

Ponnuswamy, I., Manohar, H.L., 2016. Impact of learning organization culture on performance in higher education institutions. Stud. High. Educ. 41 (1), 21-36. http://dx doi.org/10.1080/03075079.2014.914920.

Roberts, P., 1994. Creating a learning community on campus. In: Barnett, R. (Ed.),
Academic Community: Discourse or Discord? Jessica Kingsley Publishers, London, pp. 173-214.

Sellman, D., 2007. On being of good character: nurse education and the assessment of good character. Nurse Educ. Today 27 (7), 762-767. http://dx.doi.org/10.1016/j. nedt.2006.10.009.

Senge, 1990. The leader's new work: building learning organizations. Sloan Manag. Rev. 32 (1), 7-23.

Voolaid, K., Venesaar, U., 2011. A validation study of the dimensions of the learning organization questionnaire in the business school context. In: Prause, G., Venesaar, U. (Eds.), University-Business Cooperation Tallinn 2011. Berliner Wissenschafts-Verlag, Berlin, pp. 64-83.

White, J., Weathersby, R., 2005. Can universities become true learning organizations? Learn. Organ. 12 (3), 292-298. http://dx.doi.org/10.1108/09696470510592539. 